\title{
ARAŞTIRMA/RESEARCH
}

\section{Rotator manşon tendinopatisine bağlı hemiplejik omuz ağrısında proloterapinin etkinliği: pilot çalışma}

Effect of prolotherapy on hemiplegic shoulder pain due to rotator cuff tendinopathy: a pilot study

Serdar Kesikburun ${ }^{1}$, Evren Yaşar ${ }^{1}$, Berke Aras ${ }^{1}$, Bayram Kelle², Bilge Yılmaz ${ }^{1}$

${ }^{1}$ Gülhane Askeri Tip Akademisi, Fiziksel Tip ve Rehabilitasyon Anabilim Dalı, TSK Rehabilitasyon ve Bakım Merkezi, Ankara, Turkey

${ }^{2}$ Çukurova Üniversitesi Tip Fakültesi, Fiziksel Tip ve Rehabilitasyon Anabilim Dalı, Adana, Turkey

\begin{abstract}
Purpose: To investigate the effect of prolotherapy on pain and shoulder range of motion in stroke patients with hemiplegic shoulder pain due to rotator cuff tendinopathy. Material and Methods: The data of 10 patients (mean age, $64.2 \pm 11.6$ years) who had a history stroke of more than six months and underwent prolotherapy treatment were collected retrospectively. The treatment included 3 sessions of dextrose prolotherapy injections applied to rotator cuff tendon. Visual analogue scale pain scores and shoulder range of motions measured at baseline and two weeks later after end of the treatment were assessed.

Results: Visual analogue scale shoulder pain scores of the patients decreased from $8.2 \pm 1.1$ at baseline to $4.8 \pm 1.9$ after prolotherapy. The degrees of shoulder flexion and abduction increased significantly after the treatment .

Conclusion: Preliminary results in this pilot study suggested the beneficial effect of proloterapi in the treatment of hemiplegic shoulder pain.
\end{abstract}

Key words: Prolotherapy, hemiplegic shoulder, shoulder pain.

\section{GİRİŞ}

Hemiplejik omuz ağrısı, inmenin önemli komplikasyonlarından biri olup rehabilitasyon sürecini olumsuz yönde etkilemektedir ${ }^{1}$. Genellikle inme sonrası erken dönemde başlar ve kronikleşerek hastanın fonksiyonel iyileşmesini geciktirebilir.

\section{Öz}

Amaç: Rotator manşon tendinopatisine bağlı hemiplejik omuz ağrisı bulunan inmeli hastalarda proloterapi uygulamasının ağrı ve omuz eklem hareket açıklığı üzerine etkisini araştırmak.

Gereç ve Yöntem: En az 6 ay önce inme geçirmiş hemiplejik omuz ağrisına yönelik proloterapi uygulanan 10

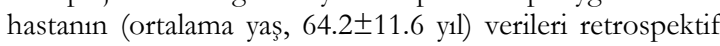
olarak toplandi. Tedavide rotator manşon tendonuna yönelik 3 seans dekstroz proloterapi enjeksiyonu içermekteydi. Hastaların tedavi öncesi ve tedavi bitiminden iki hafta sonraki vizüel analog skala omuz ağrısı skorları ve omuz eklem hareket açıklıkları değerlendirildi.

Bulgular: Hastaların proloterapi öncesi vizüel analog skala omuz ağrısı değerleri $(8.2 \pm 1.1 \mathrm{~cm})$ proloterapi sonrası kontrolde $(4.8 \pm 1.9 \mathrm{~cm})$ istatistiksel olarak anlamlı derecede azald. Omuz fleksiyonu ve abduksiyonu derecelerinde tedavi sonrası görülen artış istatistiksel olarak anlamlı bulundu..

Sonuç: $\mathrm{Bu}$ pilot çalışmada elde edilen ilk bulgular hemiplejik omuz ağrısı tedavisinde proloterapinin faydalı etkisi olduğunu önermektedir.

Anahtar kelimeler: Proloterapi, hemiplejik omuz, omuz ağr1s1

Hemiplejik omuz ağrisının en sik sebebi rotator manşon tendonipatisi olmakla beraber, glenohumeral subluksasyon, adezif kapsülit, spastisite ve kompleks bölgesel ağr1 sendromu diğer sebebler arasinda yer almaktadir². Hastalığın yönetiminde ilk amaç omuz ağrısının gelişmesini engellemek olmalıdır. Erken dönemde omuz uygun

Yazıșma Adresi/Address for Correspondence: Dr. Serdar Kesikburun, TSK Rehabilitasyon ve Bakım Merkezi, Ankara, Turkey E-mail: serdarkb@gmail.com

Geliş tarihi/Received: 11.05.2016 Kabul tarihi/Accepted: 19.06.2016 Çevrimiçi yayınlanma/Online first: 09.10.2016 
şekilde pozisyonlanmalı ve desteklenmeli, günlük yaşam aktiviteleri esnasinda hemiplejik kola uygulanacak traksiyon ve travmadan sakınılmalıdır. Ağrıya yönelik yaklaşımlar arasında omuz askısı, egzersizler, elektriksel stimülasyon, analjezik tedaviler ve kortikosteroid enjeksiyonu bulunmaktadır ${ }^{3}$.

Proloterapi, son dönemde kronik kas-iskelet sistemi patolojilerinde kullanımı giderek artan, doku iyileşmesini arttırıcı etkisi olduğuna inanılan alternatif bir girişimsel tedavi yöntemidir. Dekstroz gibi hiperozmolar sivilar kas, tendon ve ligament gibi hasarlı yumuşak doku bölgesine seanslar halinde uygulanır. Amaçlanan lokal inflamatuvar yanıt oluşturulması ile doğal iyileşme sürecinin tetiklenmesidir. Literatürde çeşitli kas, ligament ve tendon patolojilerinde uygulamaları gösterilmiştir ${ }^{4-7}$. $\mathrm{Bu}$ çalışmanın amaç, inme sonrası rotator manşon tendinopatisine bağlı hemiplejik omuz ağrısı bulunan hastalarda proloterapi uygulamasının ağrı ve omuz eklem hareket açıklığı üzerine etkisini pilot bir çalışma ile araştırmaktır.

\section{GEREÇ VE YÖNTEM}

\section{Hastalar}

Hastane bazlı bu araştırma retrospektif olarak dizayn edilen pilot bir çalışmadır. Çalışmaya TSK Rehabilitasyon Merkezi Beyin Hasarı Kliniğinde yatarak tedavi gören, 18 yaş üstü, en az 6 ay önce inme geçirmiş ve buna bağlı hemiplejisi olan, Vizüel Analog Skala (VAS) 'ya göre en az $5 \mathrm{~cm}$ ve üstünde hemiplejik omuz ağrisı olan, yapılan ultrasonografik ve klinik değerlendirmede rotator manşon tendinopatisi tespit edilen ve buna bağlı proloterapi uygulanan 10 hasta dahil edildi. Klinik değerlendirmede rotator manşon tendonunun humerus başına insersiyon yerinde palpasyonla hassasiyet varlığına, Neer ve Hawkins testlerine bakıld1. Kas iskelet sistemi ultrasonu ile yapilan omuz eklemi taramasinda, rotator manşon tendonununda ekojenite farklılıkları, tendonun fibriller paterninde bozulma ve parsiyel düzeyde tam kat olmayan tendon rüptürü varlığına bakıldı. Çalışmadan dişlanma kriterleri şu şekildedir: (1) omuz bölgesinden ameliyat olanlar, (2) inflamatuar eklem hastalığ1 öyküsü bulunanlar, (3) rutin çekilen omuz grafisinde hafif dereceden ileri omuz subluksasyonu tespit edilenler, (4) omuz kuşağ1 kaslarında özellikle omuza internal rotasyon yaptıran kaslarda modifiye ashworth skalasına göre evre 1 kasa tonusu artışı dahil spastisite tespit edilenler. Modifiye Ashworth Skalası spastisitenin şiddetinin belirlenmesinde kullanılan bir yöntemdir. Hekimin muayene sirasında hissettiği direncin subjektif olarak derecelendirmesi esasına dayanır. Bu skalaya göre; evre 0: Tonus artış1 yok, evre 1: eklem hareket açıklığının sonunda yakalama ve gevşeme veya minimal bir direnç ile karakterize hafif tonus artış1 mevcut, evre 1+: eklem hareket açıklığının yarıdan azı boyunca, minimal direncin izlendiği hafif kastonusu artışı mevcut, evre 2: kas tonusu tüm eklem hareket açıklığ boyunca ve daha fazla artmış, fakat eklemler kolayca hareket ettirilebiliyor, evre 3: pasif hareketi zorlaştıran belirgin tonus artış1 mevcuttur, evre 4: etkilenen kısımlar fleksiyon ve ekstansiyonda rijittir.Hastaların motor değerlendirmesi Brunnstrom motor evrelemesine göre yapıldı. Brunnstrom motor evrelemesi inmeli hastalarda motor düzeyi araştıran bir ölçüttür. Üst ekstremite, alt ekstremite ve el ayrı olarak değerlendilendirilir. Bu çalışmada üst ekstremite değerlendirmeleri kullanılmıştır. Hastalar en az evre 1 ve en fazla evre 6 olmak üzere skorlanır. Evre 1'de motor hareket olmadığ1 ifade edilirken; evre 6 ile normal ekstremite fonksiyonundan bahsedilir. Hastaların klinik bilgileri hasta dosyaları taranarak elde edildi. Bu çalışma için GATA Yerel Etik Kurulu'ndan onay alındi.

\section{Uygulama ve değerlendirme}

Proloterapi planlanmıs tüm hastalar, son iki hafta içerisinde sistemik kortikosteroid kullanımı, son bir ay içerisinde lokal kortikosteroid enjeksiyonu, yetersiz diyabet kontrolü, antikoagülan ilaç kullanımı, ansıtabil kalp rahatsızlığ1 varlığ1 açısından sorgulanmış ve bu durumların olmadığ1 teyit edilmiştir. Tüm hastalardan proloterapi tedavisi öncesi onam formu alınmıştır. Her hastaya iki hafta ara ile toplam 3 seans proloterapi enjeksiyonu yapıld. $\% 17$ dekstroz steril şartlar altında, rotator manșon tendonuna saçma (peppering) tekniği ile, toplam doz $10 \mathrm{ml}$ olacak şekilde uygulandi. Uygulama tendon içine ve tendon-kemik birleşme yerlerine uygulandi. Rotator manşon tendonunda hasarlı bölgeler ultrason görüntülemede ve hassas nokta palpasyonu ile tespit edildi. Proloterapi enjeksiyonu tendonun bu bölgeleri gözetilerek tendonun geneline yapıldı. Hastalarda en çok etkilenim rotator manşon kompleksisin supraspinatus tendonu kismindaydi. Hastalar ilk 1-2 gün ağrilarının artabileceği konusunda uyarıldı ve kesinlikle nonsteroidal antiinflamatuar ilaç 
almamaları belirtildi. Ağrının şiddetlenmesi durumunda parasetamol almaları önerildi. Ağrılı dönemde hasta ve refakatçilerinden hemiplejik taraf omuzu zorlayıcı hareketlerden kaçınmaları istendi.

Katılımcıların hasta dosyalarında yer alan ağrı takip formları incelendi. Ağrı takip formunda, hastaların omuz ağrısını değerlendirdikleri VAS skorları ve eklem hareket açıklığ1 değerleri mevcuttu. VAS değerlendirmelerinde $10 \mathrm{~cm}$ 'lik bir çizelge üzerinde, hastalara hissedebilecekleri en şiddetli vücut ağrısı $(10 \mathrm{~cm})$ ve hiç ağrısının olmadığ $(0 \mathrm{~cm})$ durumları düşünerek, omuz ağrısının derecesi sorgulandı. Eklem hareket açıklı̆̆1 muayenesinde, omuz fleksiyonu ve abduksiyonu değerlendirildi. Ağrısız yaptırılabilen eklem hareket açıklığ ve ağrilı olsa da yaptırılabilen maksimum eklem hareket açıklığ1 derecelerine bakıldı. Eklem hareket açılıı̆̆ ölçümleri uzman hekim olan aynı araştırmacı tarafindan gonyometre kullanılarak manuel olarak ölçüldü. Tedavi öncesi ve proloterapinin üçüncü seansindan iki hafta sonra yapilan değerlendirmeler analize dahil edildi. Kayıtlardan enjeksiyon sonrası ortaya çıkmış olası yan etkiler (ağrı, kanama, enfeksiyon vb.) sorguland1.

\section{İstatistiksel analiz}

Verilerin değerlendirilmesinde SPSS for mac 20.0 istatistik paket programı kullanıldı. Ölçümle elde edilen verilerin dağılımının normal dağılıma uygun olup olmadığ1 Kolmogorov-Smirnov testi ile belirlendi. Verilerin dağılımı normal dağılıma uygun olduğu için istatistiksel analizde parametrik testler kullanıldı. Tanımlayıcı istatistikler sürekli değișkenler için ortalama \pm standart sapma şeklinde, kategorik değişkenler ise gözlem sayısı ve (\%) olarak ifade edildi. Proloterapi tedavi sonuçlarının karşılaştırılmasında, sürekli değişkenler arasındaki farkın anlamlılığını test etmek için paired t-testi kullanıldı. $\mathrm{P}<0,05$ olan sonuçlar istatistiksel olarak anlamlı kabul edildi.

\section{BULGULAR}

Çalıșmaya 6 erkek (\%40), 4 kadın $(\% 40)$ toplam 10 inmeli hasta dahil edildi. Hastaların yaş ortalaması $64.2 \pm 11.6$ y1ldı. Hastaların 9’u (\%90) iskemik tip, 1’i $(\% 10)$ hemorajik tip inme geçirmişti. Hastaların 6'sinda (\%60) sağ taraf, 4'ünde (\%40) sol taraf ekstremiteler etkilenmişti. İnme sonrası geçen ortalama süre $7.0 \pm 3.0$ ayd1. Brunnstrom motor evrelemesi göre üst ekstremite değerlendirmesinde hastaların 8'i (\%80) evre 2, bir hasta (\%10) evre 3 ve bir hasta (\%10) evre 4'tü. Brunnstrom motor evrelemesi göre el değerlendirmesinde 6 hasta (\%60) evre 2, iki hasta (\%20) evre 3 ve iki hasta (\%20) evre 4'tü. Hastaların detaylı demografik ve klinik özellikleri Tablo 1'de gösterilmektedir.

Tablo 1. Hastaların klinik ve demografik özellikleri $(n=10)$.

\begin{tabular}{|c|c|c|}
\hline & $\mathbf{n}$ & $\%$ \\
\hline Yaş (y1l)* & $64.2 \pm 11.6$ & \\
\hline \multicolumn{3}{|l|}{ Cinsiyet } \\
\hline Erkek & 6 & 60 \\
\hline Kadın & 4 & 40 \\
\hline \multicolumn{3}{|l|}{ İnme tipi } \\
\hline İskemik & 9 & 90 \\
\hline Hemorajik & 1 & 10 \\
\hline \multicolumn{3}{|l|}{ Hemiplejik taraf } \\
\hline Sağ & 6 & 60 \\
\hline Sol & 4 & 40 \\
\hline İnme sonrası geçen süre (ay)* & $7.0 \pm 3.0$ & \\
\hline \multicolumn{3}{|c|}{ Üst ekstremite Brunnstrom motor evresi } \\
\hline Evre 2 & 8 & 80 \\
\hline Evre 3 & 1 & 10 \\
\hline Evre 4 & 1 & 10 \\
\hline \multicolumn{3}{|l|}{ E1 Brunnstrom motor evresi } \\
\hline Evre 2 & 6 & 60 \\
\hline Evre 3 & 2 & 20 \\
\hline Evre 4 & 2 & 20 \\
\hline
\end{tabular}

* Ortalama \pm standart sapma. 
Hastaların proloterapi öncesi VAS omuz ağrısı değerleri $8.2 \pm 1.1 \mathrm{~cm}$; proloterapi sonrası kontrolde $4.8 \pm 1.9 \mathrm{~cm}$ olarak saptand. VAS omuz ağrısı değişkeninin zamansal değişiminin karşılaştırılmasında proloterapi seansları öncesi ile 3 seans proloterapi uygulama sonrasi 2. hafta arasında istatistiksel olarak anlamlı azalma saptand1 $\quad(p=0.030) \quad$ (Figür 1). Omuz eklem hareketleri değerlendirmelerinde hastaların gelişim kaydettiği görüldü. Hastaların proloterapi öncesi ağrisız yapabildikleri omuz fleksiyonu değerleri $80.5 \pm 32.6$ derece ve maksimum omuz fleksiyonu değerleri 125.0 \pm 32.7 derece iken; proloterapi sonras1 kontrolde bu değerler sırasıyla 116.5 \pm 36.8 derece ve $148.5 \pm 26.8$ derece olarak saptand. Ağrisiz yapilabilen omuz fleksiyonu ve maksimum omuz fleksiyonu değişkenlerinin zamansal değişiminin karşılaştırılmasında proloterapi seansları öncesi ile 3 seans proloterapi uygulama sonrasi 2. hafta arasında istatistiksel olarak anlamlı azalma saptand 1 ( $p=<0.001$ ve $p=0.002)$ (Tablo 2). Hastaların proloterapi öncesi ağrısız yapabildikleri omuz abduksiyonu değerleri $67.5 \pm 28.2$ derece ve maksimum omuz abduksiyonu değerleri $105.0 \pm 34.7$ derece iken; proloterapi sonras1 kontrolde bu değerler sirasıly $98.0 \pm 46.5$ derece ve $132.0 \pm 40.4$ derece olarak saptand1. Ağrisız yapilabilen omuz abduksiyonu ve maksimum omuz abduksiyonu değişkenlerinin zamansal değişiminin karşılaştırılmasında proloterapi seansları öncesi ile 3 seans proloterapi uygulama sonrasi 2. hafta arasında istatistiksel olarak anlamlı azalma saptand $_{1}(\mathrm{p}=0.016$ ve $\mathrm{p}=0.002)$ (Tablo 2$)$.

Hastalarda proloterapi enjeksiyonları sonrasında ortalama iki gün süren lokal ağrıda artış dışında herhangi bir yan etki gelişmedi. Ağrı nedeniyle hiçbir hastanın tedaviyi bırakmadığı gözlendi.

Tablo 2. Sonuç ölçütlerinin proloterapi öncesi ve sonrası ortalama değişimleri.

\begin{tabular}{|l|c|c|c|}
\hline & Başlang1ç & Proloterapi sonrasi 2.hafta & p \\
\hline VAS omuz ağrısı (cm)* & $8.2 \pm 1.1$ & $4.8 \pm 1.9$ & 0.030 \\
\hline Omuz eklem hareket açıklı̆̆1 (derece)* & & & \\
\hline Fleksiyon - ağrısız & $80.5 \pm 32.6$ & $116.5 \pm 36.8$ & $<0.001$ \\
\hline Fleksiyon - maksimum & $125.0 \pm 32.7$ & $148.5 \pm 26.8$ & 0.002 \\
\hline Abduksiyon - ağrısız & $67.5 \pm 28.2$ & $98.0 \pm 46.5$ & 0.016 \\
\hline Abduksiyon - maksimum & $105.0 \pm 34.7$ & $132.0 \pm 40.4$ & 0.002 \\
\hline
\end{tabular}

Ortalama \pm standart sapma.

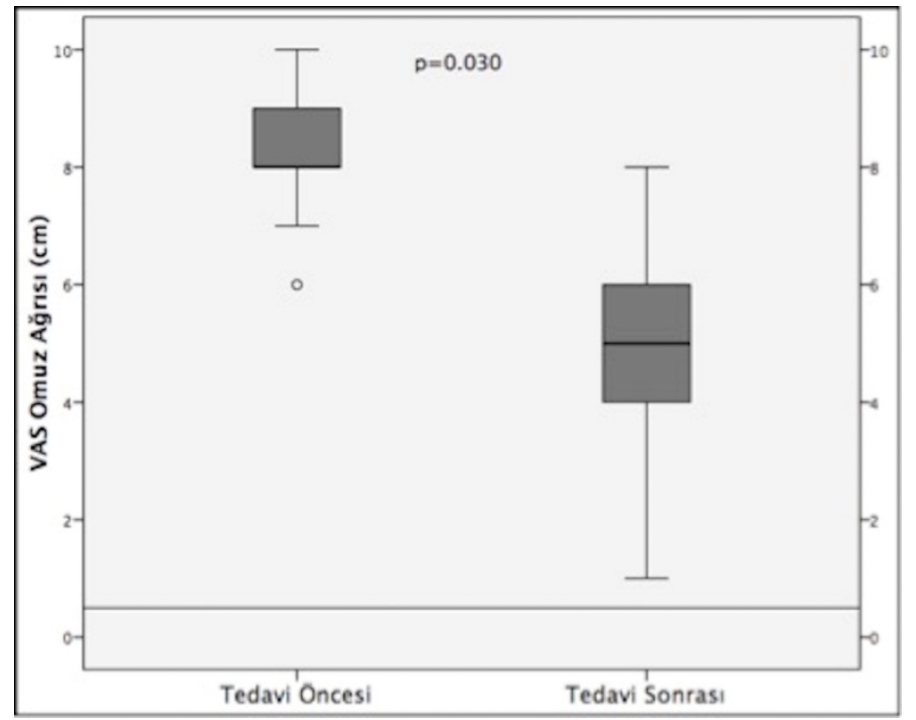

Şekil 1. VAS omuz ağrısı ölçümlerinde proloterapi seansları öncesi ile 3 seans proloterapi uygulama sonrası 2. hafta arasında görülen değişim. 


\section{TARTIŞMA}

$\mathrm{Bu}$ çalışmada inme sonrası rotator manşon tendinopatisine bağlı omuz ağrisı bulunan hastalarda iki hafta ara ile üç seans uygulanan proloterapi enjeksiyonunun etkinliği araştırıldı. Uygulama sonrasında hastaların omuz ağrıları ve eklem hareket açıklıklarında anlamlı iyileşme gerçekleştiği saptandı.

Hemiplejik omuz ağrısı, inmeli hastaların yaklaşık \%75'inde ilk 12 ay içerisinde görülen bir komplikasyondur ${ }^{8}$. Ağrının patogenezi genellikle çok faktörlüdür. Erken dönemde omuz subluksasyonu ve adezif kapsülit, geç dönemde ise spastisite ağr1 kaynağ1 oluşturabilmektedir. Ancak Rotator manşon tendinopatileri, hemiplejik omuz ağrısının en sik sebebi olup tüm inmeli hastaların 1/3'ünde görülmektedir. İnmeli hastalarda görülen iç rotasyon spastisitesi ve diş rotator kaslardaki kuvvetsizlik, pasif hareketler sirasinda akromiyon altından geçen rotator tendonlarda sıkışmaya ve yırtılmaya sebep olmaktadır. Özellikle dış rotasyona getirilmeden yapilan abduksiyon hareketlerinde tendon hasarı riski artmaktadır. Tanı manyetik rezonans görüntüleme ve kas iskelet ultrasonografisi ile konulabilirken, subakromiyal alana yapilan lokal anestezik enjeksiyonu sonrası ağrının azalması da tanıya yardımcıdır. Hemiplejik omuz ağrısına yaklaşımda ilk basamak inme sonrasında bu komplikasyonun oluşmasını engellemektir. Uygun pozisyonlama, omuz askısı ve bandajlar bu amaçla sıklıkla kullanılmaktadır. Ağrı durumlarında basit analjezikler, egzersizler, transkutanöz elektriksel sinir stimulasyonu, fonksiyonel elektriksel stimulasyon ilk olarak başvurulan yöntemlerdir ${ }^{10}$. Dirençli ağrılarda botulinum toksin enjeksiyonu, supraskapular sinir bloğu, intra-artiküler kortikosteroid enjeksiyonu denenebilir ${ }^{11}$.

Proloterapi, kronik tendon, ligament ve kas hastalıklarında rejenerasyon mekanizmalarının tetiklenmesi esasina dayanan alternatif bir tedavi yöntemidir. Enjeksiyon ajanı olarak hiperozmolar sivilar kullanılmakta olup hiperozmolar dekstroz ve sodyum morrhuate en sik kullanilan ajanlardır. Proloterapinin etki mekanizması tam olarak açıklanamamakla birlikte hiperozmolar dekstroz inflamatuar kaskadı stimüle ederek yerel iyileşmeyi ve doku rejenerasyonunu arttırmaktadır. Hücreler aras1 dekstroz seviyesinin artmas1 fibroblastik sitokinlerin üretimini uyarmaktadır ${ }^{12}$. Dekstrozun etkilerine ek olarak, solüsyonun volüm etkisi ve iğnelemenin yarattığı lokal travmanın inflamatuvar sürecin stimülasyonuna katk1 sağladığ1 varsayılmaktadır. $\% 10$ dekstroz enjeksiyonunun kullanıldığ1 randomize kontrollü hayvan çalışmasında konnektif doku genişliğinde artış, kollajen demetlerinde kalınlaşma ve yük taşıma kapasitelerinde artış saptanmıştır ${ }^{13}$. Ayrıca dekstroz enjeksiyonu sonrasinda dekstrozun lezyon yerinde direk analjezik etkisinin de bulunabileceğini gösteren çalışmalar vardır ${ }^{14}$.

Literatüre bakıldığında, proloterapinin aşil tendon, ön çapraz bağ, lateral epikondilit gibi yumuşak doku lezyonlarında kullanıldığı görülmektedir ${ }^{4-6}$. Rotator manşon tendinopatisine yönelik proloterapinin etkinliğinin araştırıldığı bir adet çalışma bulunmaktadır ${ }^{7}$. Bertrand ve arkadaşları ${ }^{7}$ yapmış olduğu randomize çalışmada hastaları dekstroz ve salin enjeksiyonu olarak iki gruba ayırmış, hastalara birer ay ara ile 3 enjeksiyon uygulamış ve uygulama sonrasinda dekstroz enjekte edilen grupta ağr1 skorunda anlamlı azalma saptanırken, ultrasonografik değişiklikler açısıdan anlamlı farklılıklar saptanamamıştır. Bu çalışma inmeli hastalarda görülen rotator manşon hasarına bağlı hemiplejik omuz ağrısına yönelik yapılan proloterapi enjeksiyonunun etkinliğini araştıran ilk çalışmadır. Bu çalışmada iki hafta ara ile yapılan 3 enjeksiyon sonrasında omuz ağrisında anlamlı iyileşme olduğu saptanmıştır. $\mathrm{Bu}$ bulgular, Bertrand ve arkadaşlarının ${ }^{7}$ yapmış olduğu çalışma ile uyumluluk göstermektedir.

Hemiplejik omuzda genellikle eklemin pasif hareketleri sırasında ağrilarında artma meydana gelebileceği gibi istirahat ağrisından da siklıkla bahsedilir. Hareket esnasinda artan ağr1 hastalarda egzersizlere karşı isteksizlik yaratmakta ve zamanla omuz ekleminde hemiplejik omuz ağrısının önemli bir bulgusu olan eklem hareket kisitlilığ1 oluşmaktadır ${ }^{15}$. Ağrının şiddeti ile eklem hareket k1sıtlllı̆̆ın birlikteliği bu çalışmada yer alan hastalarda da görülmektedir. Proloterapi sonrasinda omuz ağrısindaki azalma ile maksimum ve ağrilı eklem hareket açıklıklarında düzelme beraber ortaya çıkmıştır.

Pilot çalışma olarak planlanan bu araştırmada bazı limitasyonlar bulunmaktadir. Verilerin retrospektif olarak elde edilişi, kontrol grubunun olmaması, hasta sayısının az olması ve takip süresinin kısa olması 
başta gelen limitasyonlardır. Gelecekte proloterapinin hemiplejik omuz ağrısında etkilerinin değerlendirileceği prospektif dizayn edilecek, randomize kontrollü çalışamalara ihtiyaç vardır. Proloterapi uygulama tekniğine bakıldığında ise, tedavi protokolü açısından henüz standardizasyon olmayışı bir limitasyon olarak kabul edilebilir. Optimal sonuç için kaç seans proloterapi gerektiği, uygulama sıklı̆̆1, hangi bölgelere uygulanacağ1, proliferantın içeriği, uygulama sonrası yaklaşımlar konusunda yeterli bilgi bulunmamaktadır. Gelecek çalışmaların bu konuları aydınlatması gerekmektedir. $\mathrm{Bu}$ çalışmada müdahale sonrası hastalarda görülen gelişmeler ağnı seviyesi ve eklem hareket açılı̆̆ğ ölçümleri ile takip edilmiştir. Doku iyileşmesine katkısı olduğu düşünülen proloterapinin tendon morfolojisini de düzeltip düzeltmediği yapılacak ultrason takipleri ile gelecek çalışmalarda ortaya konabilir.

Sonuç olarak bu pilot çalışmada inmeli hastalarda rotator manşon tendinopatisine bağlı hemiplejik omuz ağrisında ve eklem hareket kisitliliğında proloterapi enjeksiyonun etkili ve güvenli olarak kullanabileceğine dair ilk bulgular elde edilmiştir. Bu sonuçlar gelecekte yapılacak geniş çaplı çalışmalara yol gösterici kabul edilebilir. Bilinen standart tedavilere cevap vermeyen hemiplejik omuz ağrısında, proloterapi alternatif bir tedavi yöntemi olarak düşünülebilir.

\section{KAYNAKLAR}

1. Dromerick AW, Edwards DF, Kumar A. Hemiplegic shoulder pain syndrome: frequency and characteristics during inpatient stroke rehabilitation. Arch Phys Med Rehabil. 2008;8:1589-93.

2. Wilson RD, Chae J. Hemiplegic Shoulder Pain. Phys Med Rehabil Clin N Am. 2015;26:641-55.

3. Bender L, McKenna K. Hemiplegic shoulder pain: defining the problem and its management. Disabil Rehabil. 2001;23:698-705.

4. Scarpone M, Rabago DP, Zgierska A, Arbogast G, Snell E. The efficacy of prolotherapy for lateral epicondylosis: a pilot study. Clin J Sport Med. 2008;18:248-54.

5. Yelland MJ, Sweeting KR, Lyftogt JA, Ng SK, Scuffham PA, Evans KA. Prolotherapy injections and eccentric loading exercises for painful Achilles tendinosis: a randomised trial. $\mathrm{Br} \mathrm{J}$ Sports Med. 2011;45:421-8.

6. Reeves KD, Hassanein KM. Long-term effects of dextrose prolotherapy for anterior cruciate ligament laxity. Altern Ther Health Med. 2003;9:58-62.

7. Bertrand H, Reeves KD, Bennett CJ, Bicknell S, Cheng AL. Dextrose Prolotherapy Versus Control Injections in Painful Rotator Cuff Tendinopathy. Arch Phys Med Rehabil. 2016;97:17-25.

8. Ward AB. Hemiplegic shoulder pain. J Neurol Neurosurg Psychiatry. 2007;78:789.

9. Lo SF, Chen SY, Lin HS, Jim YF, Meng NH, Kao MJ. Arthrographic and clinical findings in patients with hemiplegic shoulder pain. Arch Phys Med Rehabil. 2003;84:1786-91.

10. Dromerick AW, Edwards DF, Kumar A. Hemiplegic shoulder pain syndrome: frequency and characteristics during inpatient stroke rehabilitation. Arch Phys Med Rehabil. 2008;89:1589-93.

11. Yasar E, Vural D, Safaz I, Balaban B, Yilmaz B, Goktepe AS et al. Which treatment approach is better for hemiplegic shoulder pain in stroke patients: intra-articular steroid or suprascapular nerve block? a randomized controlled trial. Clin Rehabil. 2011;25:60-8.

12. Pradhan L, Cai X, Wu S, Andersen ND, Martin M, Malek J et al. Gene expression of pro-inflammatory cytokines and neuropeptides in diabetic wound healing. J Surg Res. 2011;167:336-42.

13. Yoshii Y, Zhao C, Schmelzer JD, Low PA, An KN, Amadio PC. Effects of multiple injections of hypertonic dextrose in the rabbit carpal tunnel: a potential model of carpal tunnel syndrome development. Hand (N Y). 2014;9:52-7.

14. Smigel L, Reeves KD, Lyftogt J, Rabago D. Analgesic effect of caudal 5\% dextrose in water in chronic low back pain. Arch Phys Med Rehabil. 2015;96:103.

15. Roy CW, Sands MR, Hill LD, Harrison A, Marshall $\mathrm{S}$. The effect of shoulder pain on outcome of acute hemiplegia. Clin Rehabil. 1995;9:21-7. 